\title{
An Online Residential Cooling Load Calculation Program
}

\author{
K. Yeong and F. C. Lai \\ School of Aerospace and Mechanical Engineering \\ University of Oklahoma \\ Norman, Oklahoma 73019
}

\begin{abstract}
This paper presents an online interactive program and how it can benefit students of engineering and architecture in the learning of residential cooling load calculation. This program is also helpful in the training of professional engineers and architects in the basic load calculations. It can be used as a stand-alone teaching aid or an add-on component for any online course dealing with air-conditioning or architectural design. The implementation of this online load calculation program has greatly enhanced the learning experience of our students in the study of airconditioning systems and the design of energy-efficient buildings.
\end{abstract}

\section{Introduction}

To design an energy-efficient building and size the air-conditioning system properly, a good estimate of the cooling load is very important. The cooling load of a building represents the heat that must be removed from the interior of a building to maintain the thermal comfortable zone for its occupants. The cooling load is different from the heat gain since some of the heat gains, such as solar radiation, are absorbed by the building's structural components and do not appear as the cooling load until sometime later. ${ }^{1,2}$ Cooling load is generally divided into sensible and latent loads. Sensible cooling load includes heat gain through building envelopes, heat gain due to infiltration and ventilation, as well as heat gains from solar radiation, lights, equipment and occupants. Sensible cooling load is manifested by a rise in the temperature of the air. On the other hand, the latent cooling loads are mainly due to air exchange, equipment operation and occupant's activity, which become important when there is a significant difference in the humidity of air. The calculation of cooling load is an important subject for both engineering and architecture students, which is usually taught in several undergraduate courses (for example, these include Heat Transfer, Design of Thermal-Fluid Systems, Air-Conditioning Systems, Environmental Systems in Architecture, Environmental Control for Buildings, and Advanced Building Systems in our engineering and architecture curricula).

Several methods have been developed for the calculation of cooling load ${ }^{3}$. These include the method of Cooling Load Temperature Difference/Solar Cooling Load Factors/ 
Internal Cooling Load Factors (i.e., CLTD/SCL/CLF), the method of the Total Equivalent Temperature Differential values and Time Averaging (TETD/TA), and the method of Transfer Function (TFM). Although recently there is a strong push for the Transfer Function method, the CLTD/SCL/CLF method still remains the most popular one among these methods because of its simplicity. In fact, the data used in the CLTD/SCL/CLF method are derived from the more complicated Transfer Function method. With the availability of these derived data (usually in the form of tables and charts), the calculation of cooling load can be done in a much simpler and straightforward way without resorting to a computer. When used properly, the results obtained from the CLTD/SCL/CLF method are as accurate and reliable as those from the Transfer Function method. However, even for the simplest method like CLTD/SCL/CLF, the calculations can sometimes become very tedious, particularly when one needs to reiterate the changes of design parameters in the search for an optimal design. Thus, there are several commercial packages available for the load calculation. With the help of computer, the load calculations can be made easy and cost-effective ${ }^{4}$. Currently, there are several commercial packages available in the market not only for the cooling load calculations, but also for other applications of heating, ventilating, and air-conditioning (HVAC) systems. Some of the most well known ones include HVAC-Calc by HVAC Computer Systems, Ltd. ${ }^{5}$, E20-II HAP (Hourly Analysis Program) by CARRIER Corp. ${ }^{6}$, and BLAST (Building Loads Analysis and System Thermodynamics) Program developed by USACERL ${ }^{7}$. These commercial packages have many built-in features; for instance, the calculation of heat loss and heat gain of a building, sizing of the air conditioner, rating of the airflow in each room, and the layout of ductwork. As such, the price of a commercial package is usually expensive. In addition, these commercial packages have been specifically designed for contractors. A user must have some special training or prior experience before he can use the package comfortably. Clearly, they are not suitable for beginners, particularly for students in their early stage of study.

The purpose of the present study is to develop an online interactive program that can be used as a teaching aid for classes that deal with the subject of cooling load calculation. With the availability of the program, faculty can effectively demonstrate and students can easily understand how various design parameters affect the cooling load. More importantly, one can perform the load calculations much more efficiently without having to look up the values of design parameters and building's material properties from tables or charts in any reference book.

\section{An Overview of the Online Residential Cooling Load Calculation Program}

\section{General Information}

This residential cooling load calculation program is currently available online and it can be accessed at the following URL, http://coecs.ou.edu/flai/www/coolingload/home.htm. This program is compatible with any browser and is best viewed with a screen resolution of $800 \times 600$ or higher (Fig. 1). Most of the contents in this program were created using Macromedia Dreamweaver as the authoring software (Fig. 2) whereas the main calculation page was developed using Director as the authoring software (Fig. 3). The simulation results produced by Director are exported as Shockwave files. The advantage of using Shockwave movies is that their file size is usually small and hence can be quickly downloaded through the Web. 


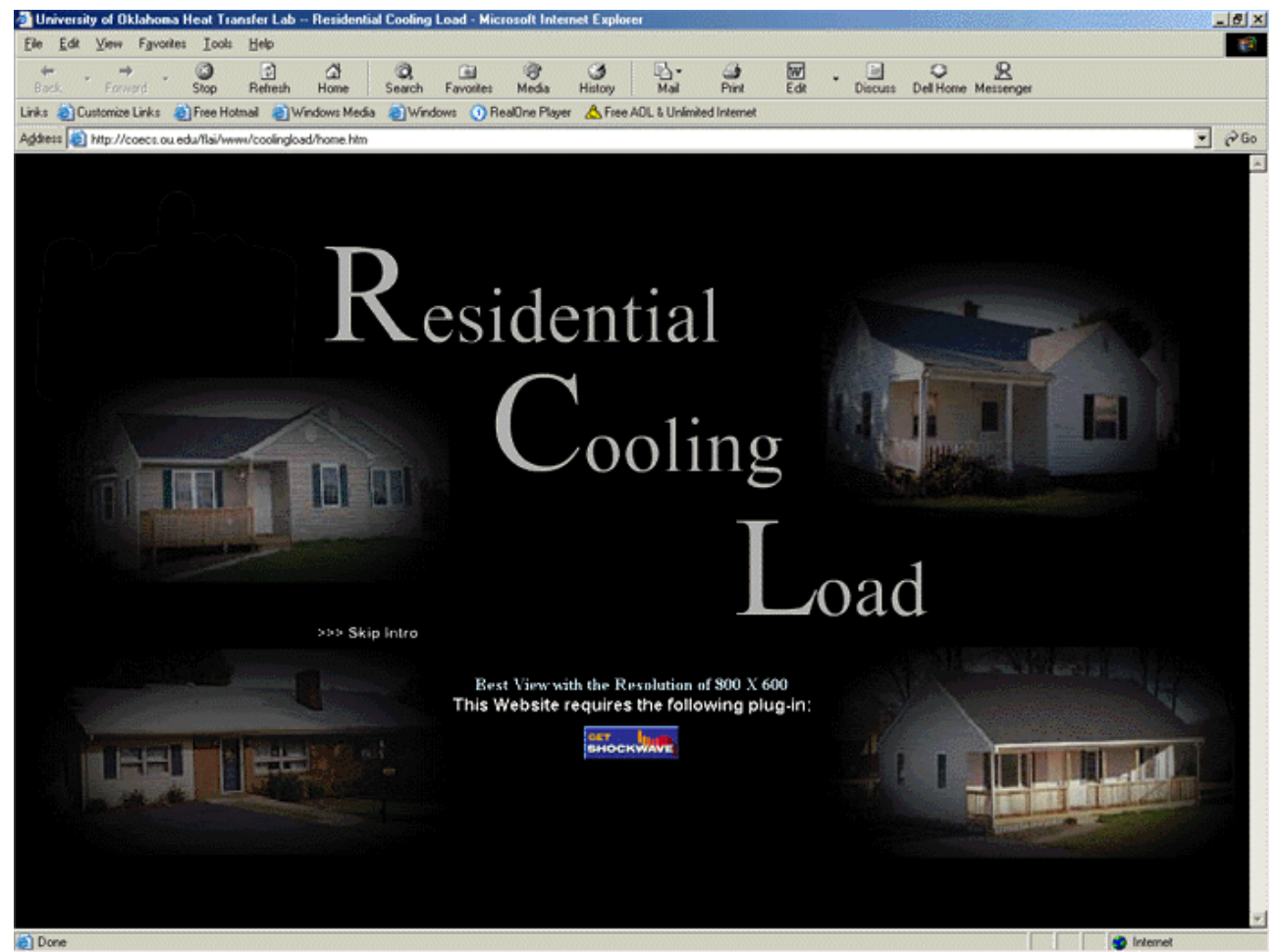

Figure 1. Opening page of the online residential cooling load calculation program.

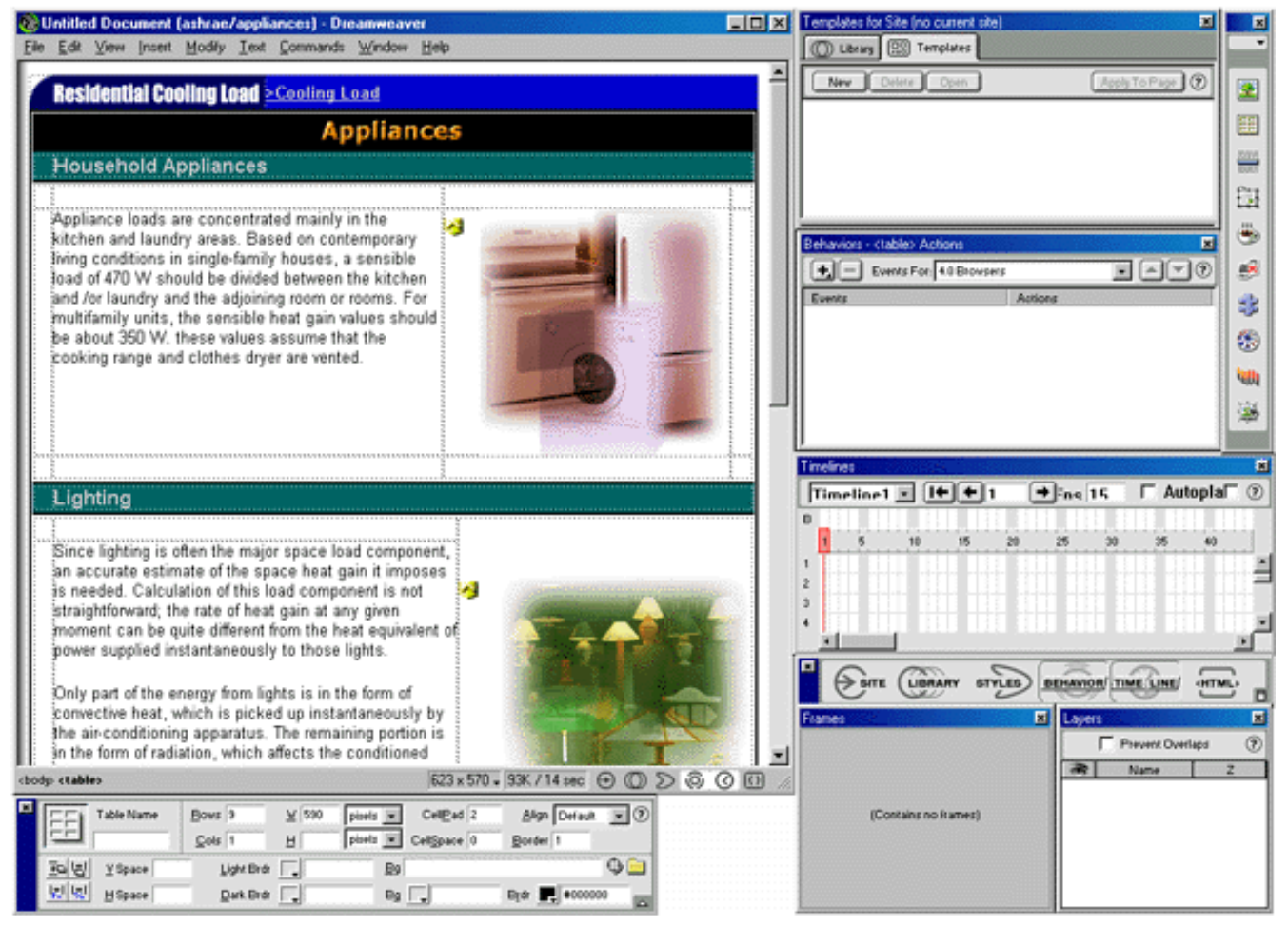

Figure 2. Snapshot of Macromedia Dreamweaver interface.

Proceedings of the 2004 American Society for Engineering Education Annual Conference \& Exposition Copyright (C) 2004, American Society for Engineering Education 


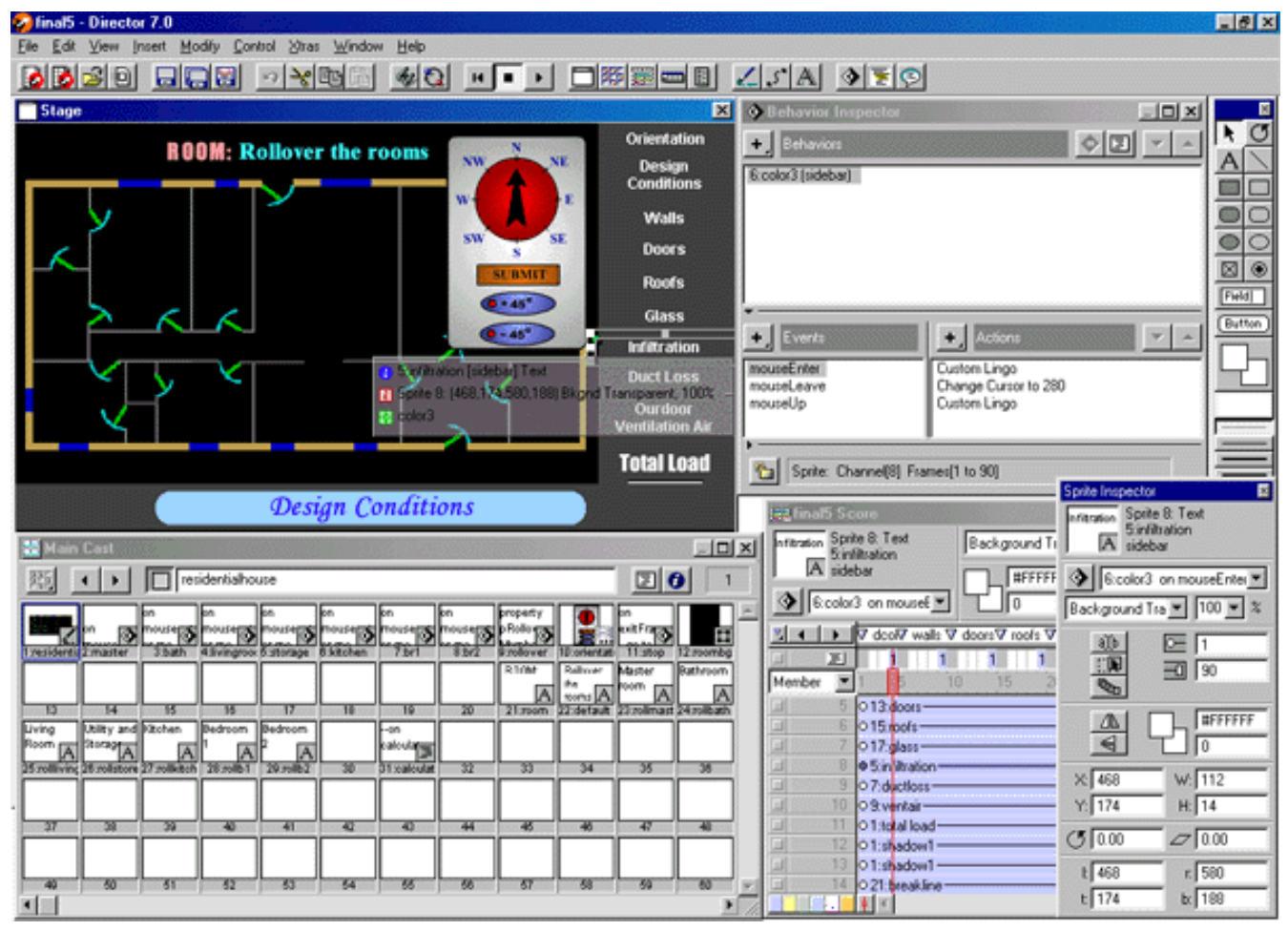

Figure 3. Snapshot of Macromedia Director interface.

Since this program is designed for beginners, it begins with some general information about residential buildings, cooling load, factors that affect the load, and methods for the load calculation, etc. This information is presented by using an integration of text, pictures, and animations (Fig. 4). The purpose of this introduction is to provide the user a basic idea about cooling load and some design considerations. An experienced or a returned user can skip the introduction and go directly to the calculation program. After having understood the concept of cooling load and the methodology of calculation, an user can start running the program and perform the cooling load calculation for a model house. The selected model house is taken from an example in the ASHRAE Handbook ${ }^{8}$.

\section{Load Calculation Program}

For the present program, the load calculation is based on the CLTD/SCL/CLF method. Only the cooling load for a residential building is considered. In addition, the floor plan of the building is fixed and it is chosen to be a single-family detached house (Fig. 5). The airconditioning equipment is located in the garage where no air-conditioning is provided. In the calculations, the internal loads contributed by occupants and appliances are predetermined for simplicity. Thus, the factors that have direct influences on the cooling load of the house are: building orientation, outdoor and indoor design conditions, construction tightness, construction materials, infiltration, and ventilation of outdoor air. The equations used for the load calculation are summarized below.

$$
\mathrm{q}_{\mathrm{d}}=\mathrm{U}_{\mathrm{d}}(\mathrm{CLTD})_{\mathrm{d}} \mathrm{A}_{\mathrm{d}}
$$




$$
\begin{aligned}
& \mathrm{q}_{\mathrm{w}}=\mathrm{U}_{\mathrm{w}}(\mathrm{CLTD})_{\mathrm{w}} \mathrm{A}_{\mathrm{w}}, \\
& \mathrm{q}_{\mathrm{r}}=\mathrm{U}_{\mathrm{r}}(\mathrm{CLTD})_{\mathrm{r}} \mathrm{A}_{\mathrm{r}}, \\
& \mathrm{q}_{\mathrm{f}}=\mathrm{U}_{\mathrm{f}}(\mathrm{CLTD})_{\mathrm{f}} \mathrm{A}_{\mathrm{f}}, \\
& \mathrm{q}_{\mathrm{g}}=(\mathrm{GLF}) \mathrm{A}_{\mathrm{g}}, \\
& \mathrm{q}_{\mathrm{i}}=1.2 \mathrm{ACH}(\text { room volume })(\Delta \mathrm{T}) 1000 / 3600, \\
& \mathrm{Q}_{\text {total }}=\mathrm{LF} \times\left(\mathrm{Q}_{\text {sensible }}\right)
\end{aligned}
$$

where q's are the sensible cooling load components from each contributing factor, U's are the overall heat transfer coefficients, CLTDs are the cooling load temperature differences, A's are the areas of applicable surfaces, GLF is the glass load factor, $\mathrm{ACH}$ is the air change per hour, $\Delta \mathrm{T}$ is the temperature difference between the outdoor and indoor air, and LF is the latent load factor. The subscripts d, w, r, f, g, and i represent the load components contributed from door, wall, roof, floor, glass (window), and infiltration, respectively. The U-factors, CLTDs, ACH, and GLFs are all related to the input data: building orientation, design conditions, and building materials (Fig. 6). The determination of their values will be discussed in detail in the following sections.

\section{Inputs to the Calculation Program}

Throughout the program, the user can provide input by either choosing an item from the drop down menus, or simply typing in the value in the text field. In all input pages, there appears a yellow box in the bottom screen. This box is used to provide the user with some useful information to help him navigate through this program. The corresponding equation used for the load calculation is also shown in the input page for quick reference. The details of the calculation are available in the "Help" section in the main menu. In addition, the summaries, tables and charts used in the cooling load calculations are provided through links in the help sections. The U-factors for various constructions materials accompanied by the building codes and types are also provided in the tabular forms for easy reference.

\section{(a) Building Orientation}

When the program is first called up (from the main menu bar), the floor plan of the model house and a compass are displayed in a new page on a separate window (Fig. 7). First, the user needs to specify the orientation of the house. There are eight possible choices for the orientation; north, south, east, west, northeast, northwest, southeast, and southwest. The default orientation of the house is west as is clear from the figure. The blue arrow of the compass always points to the north. After the user selects his preferred orientation, the arrow will re-align itself in accordance with the orientation specified. The orientation of the building is crucial in determining the CLTDs for walls and doors, as well as the GLFs for windows.

\section{(b) Design Conditions}

Next, the user needs to specify the design conditions from the local menu bar that is displayed on the input page. There are four design conditions to be specified; latitudes, outdoor

Proceedings of the 2004 American Society for Engineering Education Annual Conference \& Exposition

Copyright (c) 2004, American Society for Engineering Education 


\begin{tabular}{|l|l|}
\hline Universily of Oklahoma Heat Transfer Lab - Residential Cooling Load - Microsoft Internet Explorer \\
\hline Ladress
\end{tabular}

Figure 4. Information page of the online residential cooling load calculation program.

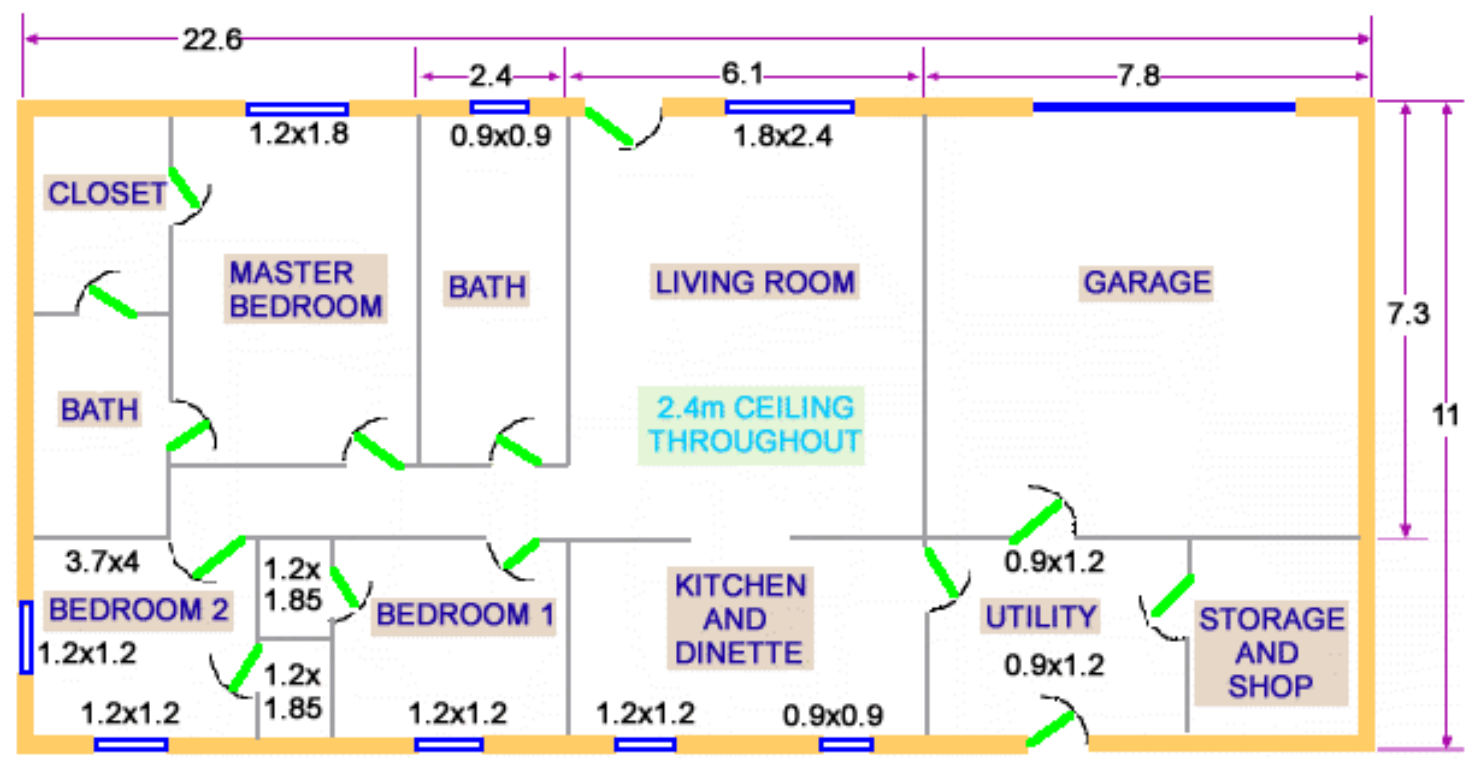

All Dimensions in meters

Figure 5. Floor plan of the model house ${ }^{8}$.

dry-bulb temperatures, daily temperature range as well as the humidity ratio. The latitude is used for the selection of GLF values from the corresponding tables. The temperature data are used in the selection of ACHs, CLTDs, and GLFs. In this program, the dry-bulb temperatures

Proceedings of the 2004 American Society for Engineering Education Annual Conference \& Exposition Copyright (C) 2004, American Society for Engineering Education 


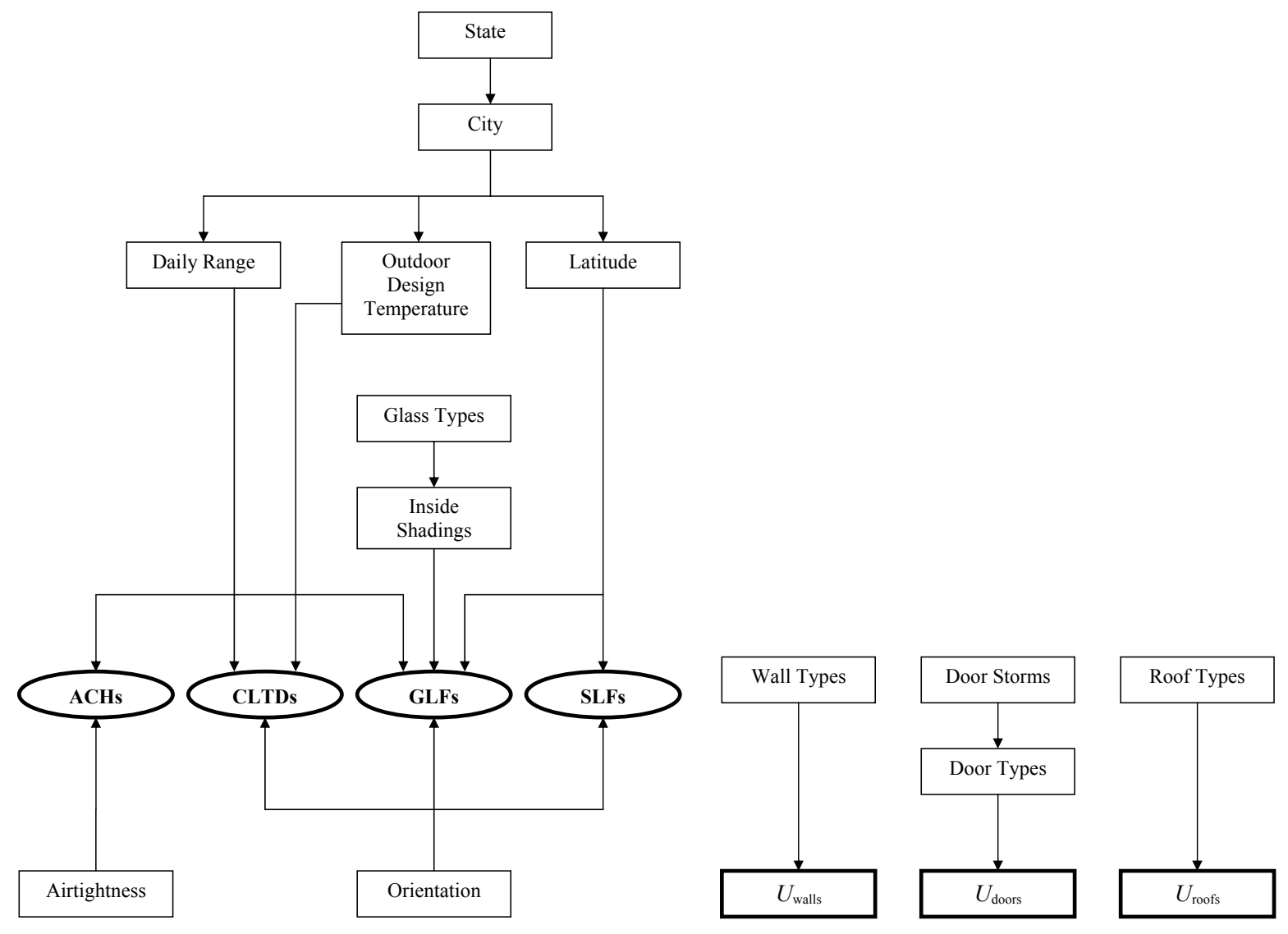

Figure 6. Relations among the cooling load factors and the input data.

corresponding to one-percentile annual cumulative frequency of occurrence are in use. These values represent the outdoor dry-bulb temperatures that are exceeded on average by one percentage of the total number of hours in a year. Therefore, this implies that on average the outdoor dry-bulb temperatures in 88 (out of 8760) hours exceed those recorded. One percentile is chosen since these data are more conservative, thus providing a more accurate and reliable result from the cooling load calculation. The humidity ratio is used to determine the LF in conjunction with the construction airtightness. The humidity ratio is also based on onepercentile annual values to be consistent with the dry-bulb temperature. All the CLTD values for the residential building are based on the assumption that the indoor temperature swing is no more than $1.5{ }^{\circ} \mathrm{C}$ on a design day when the residence is conditioned 24 hours per day and the thermostat is set at $24{ }^{\circ} \mathrm{C}^{8}$.

Since these design conditions are determined solely by the location of the house, the user needs to select the location of the house (state and city) to fix these conditions. The location of the house can be selected from a drop down menu, which includes more than 400 cities in the United States. If the location of the house is not on the list provided, the user will have to choose the nearest-by city with the same climate. These data are based on the climate design information database listed in the ASHRAE Handbook ${ }^{8}$. 


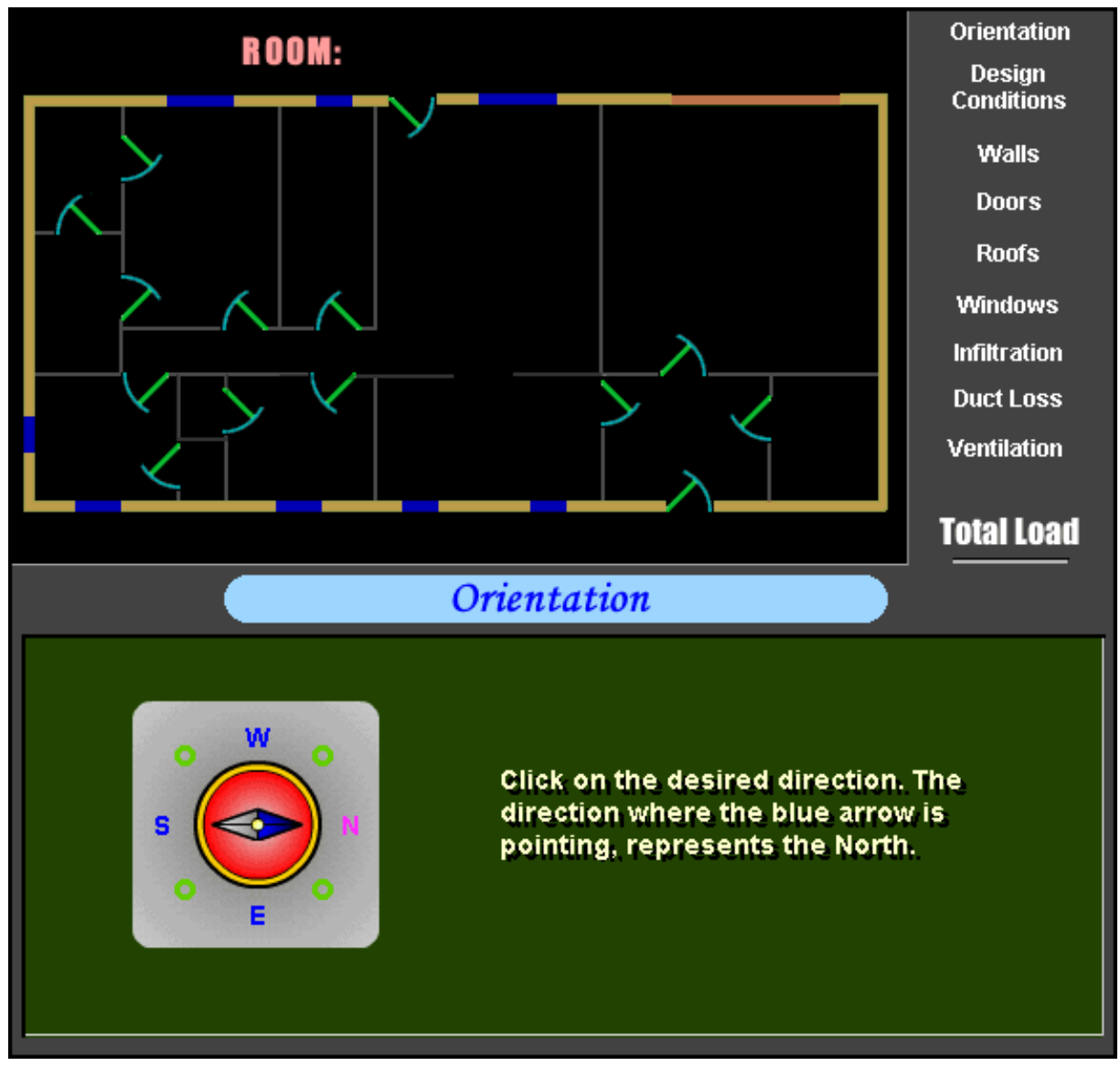

Figure 7. Main page for load calculation.

\section{(c) Building Structures}

For cooling load calculation, the building structural components that need to be specified are wall, roof, door, and windows. In addition, information related to infiltration, ventilation and duct loss is also required. When activated, each structural component opens up its own input page as described below.

\section{c1. Wall}

With the area of the walls already defined, the sensible cooling load for each room and the whole building can be calculated after the user defines the wall types. According to the ASHRAE Handbook ${ }^{8}$, there are seven wall groups, which include 41 different wall assemblies. Thus, the heat transfer coefficients for these 41 types of walls along with their corresponding building codes are all pre-stored in this program. When clicking on the wall type, the user can choose an appropriate one from these 41 options (Fig. 8a). At the same time, the corresponding heat transfer coefficient is displayed in the U-factor box below the wall types menu (Fig. 8b). This allows the user to keep track of the overall heat transfer coefficient for each wall type.

\section{c2. Roof}

In a similar procedure as wall, the user can choose the roof type from 42 roof assemblies with a wide variety of components, insulation, and mass (with the options of the predominant

Proceedings of the 2004 American Society for Engineering Education Annual Conference \& Exposition Copyright (C) 2004, American Society for Engineering Education 


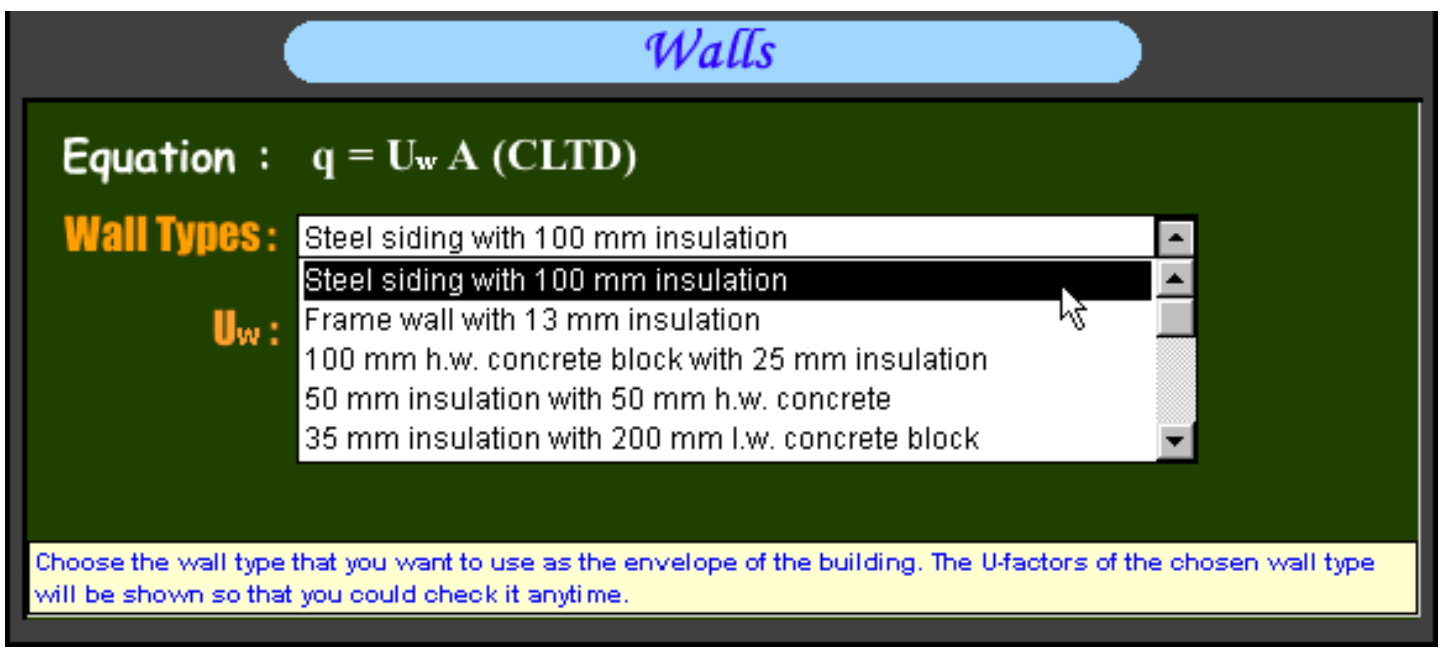

(a)

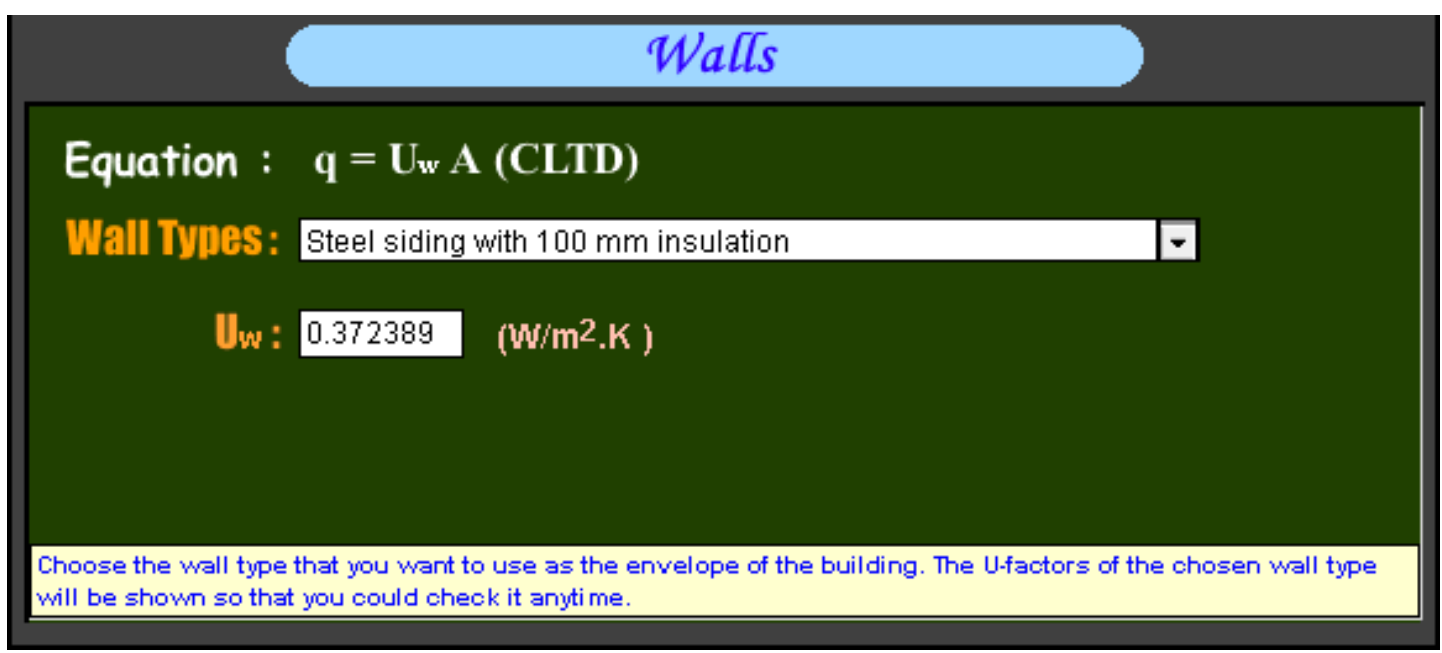

(b)

Figure 8. Input page for walls.

mass concentrated near the inside surface, outside surface, or essentially homogeneous with the overall construction).

\section{c3. Door}

Doors are generally divided into two categories; wood doors and steel doors. In each category, it can be further divided into no storm door, wood storm door, and metal storm door. Each of these combinations can result in different transmission coefficient values. Thus, the user has to first determine the storm type for the door. After that, the user can only choose the door type that is consistent with the storm that has been chosen. The corresponding U-factor will be shown on the screen, along with the equation used for the calculation of cooling load. It should 
be noted that the U-factors are calculated using the combined outdoor heat transfer coefficient of $17.0 \mathrm{~W} / \mathrm{m}^{2} \cdot \mathrm{K}$, indoor coefficient of $8.3 \mathrm{~W} / \mathrm{m}^{2} \cdot \mathrm{K}$, and the specified constructions ${ }^{8}$.

\section{c4. Fenestration}

In the calculation of the sensible cooling load contributed by windows or glass in a residential building (Eq. (5)), the most important parameter is the Glass Load Factors (GLF). The value of GLF is determined by the location and orientation of the building, the glass type, and the shading. There are four types of glasses that are commonly used in a residential building, which are regular single glass, regular double glass, heat-absorbing double glass and clear triple glass. The user can select the glass type through a drop down menu. After choosing the glass type, the user needs to specify if the building has inside shading. There are three options for the inside shading: (1) No inside shading, (2) Draperies, venetian blinds, translucent roller shades, fully drawn, (3) Opaque roller shades, fully drawn. As soon as the glass type and inside shading are selected, the GLF for the sunlit glass can be determined.

In addition, the user can specify if there is an overhang on the top of the window. The overhang width can vary from 0 (which means no overhang) to 0.60 meter. This overhang width (w) is used in conjunction with the Shade Line Factor (SLF) and the window's height (h) to calculate the corresponding shaded glass area as shown in the following equation,

$$
\mathrm{A}_{\text {shaded }}=\mathrm{SLF} \cdot \mathrm{w} \cdot \mathrm{h} \text {. }
$$

The sunlit glass area is thus the difference between the whole glass area and the shaded glass area. The user must note that the roof overhangs do not effectively shelter northeast and northwest facing windows from sunlight. As such, windows in these two orientations should not be considered shaded. The north facing windows however is considered to be completely shaded.

\section{c5. Infiltration}

Infiltration is the uncontrolled inward flow of unconditioned outdoor air through cracks and openings on the building envelope because of the pressure difference across the envelope ${ }^{9}$. All buildings have some air leakage or infiltration, no matter how well they are designed. This produces a heat gain because the temperature and humidity of the outdoor air must be reduced to the indoor design conditions. As shown earlier, the cooling load due to infiltration is calculated by Eq. (7). Except for the air change per hour (ACH), the data required for this calculation have already been determined by the design conditions. Air change per hour is a measure of infiltration. An infiltration rate of $1 \mathrm{ACH}$ means that there is enough air leakage into the house (and out, obviously) to completely change the air in the house in one hour. To determine $\mathrm{ACH}$, the user needs to specify the construction type, which is usually classified into three categories; loose, medium and tight constructions. The definition of these three construction types are given below ${ }^{8}$.

1. Tight: Construction with close fitting doors, windows, and framing. New houses with full vapor retarder, no fireplace, well-fitted windows, weather-stripped doors, one story, and less than $140 \mathrm{~m}^{2}$ floor area. 
2. Medium: New two-story frame houses or one-story houses which are more than ten years old with average maintenance, a floor area greater than $140 \mathrm{~m}^{2}$, average fit windows and doors, and a fireplace with damper and glass closure.

3. Loose: Houses which are more than twenty years old, of average maintenance, having a fireplace without damper or glass closure, or having more than an average number of vented appliances.

After the user selects the construction type, the summer air exchange rates as a function of airtightness can be found from a table built in the program with the already defined outdoor temperatures.

\section{c6. Ventilation}

In general, the building envelope is leaky enough so that the infiltration is adequate for maintaining a good indoor air quality. However, this assumption sometimes cannot be met due to difficulties such as low infiltration when natural forces (temperature difference and wind) are weak, unnecessary energy consumption when such forces are strong, lack of control to meet changing needs, and lack of opportunity to recover the energy. As such, a ventilation system is needed. Ventilation systems employ either natural or mechanical forces to produce and change airflow. Any appraisal of the functioning of a ventilation system should be given due consideration to its ability to eliminate or at least minimize the undesirable conditions such as heat and moisture given off by occupants, excessive heat from all sources, odors, bacteria, smoke and fog productions, as well as dirt, dust lint, etc.

The present program further calculates the cooling load contributed by the ventilation after the normal infiltration has been calculated. For example, if the construction of the house is medium and its outdoor temperature is $35^{\circ} \mathrm{C}$, then the infiltration rate is $0.5 \mathrm{ACH}$. Assuming that additional outdoor air of $50 \%$ of its normal infiltration rate is needed to assure good indoor air quality, the total infiltration rate is then increased to $0.75 \mathrm{ACH}$. Therefore, the original cooling load by infiltration will be multiplied by $50 \%$ after including the $50 \%$ increase in the infiltration rate due to ventilation. In the ventilation load section, an editable text box appears with a default value (which is $50 \%$ ) for the increase of infiltration rate. This default value can be overwritten by the user based on the actual condition.

\section{c7. Occupancy and Appliances}

For the present program, it is assumed that the sensible heat gain comes from occupants mainly in the sedentary state, which is measured to be 67 Watts per occupant. If the number of occupants is not given, it is then assumed two occupants for the master bedroom and one occupant per each additional room. Based on the current living conditions in most single-family houses, the appliance and light loads of 940 Watts are divided between kitchen, utility room and the living rooms. These values are based on the assumption that the cooking range and dryer are vented.

\section{c8. Duct Loss}

In this program, it is assumed that cooling is provided by a central air-handling unit through a distributing duct. If the duct is inside the conditioned space as it is for many houses, then it has no heat loss or heat gain. Suppose that the duct is outside the conditioned space (such

Proceedings of the 2004 American Society for Engineering Education Annual Conference \& Exposition Copyright @ 2004, American Society for Engineering Education 
as in the attic, crawl space, or other unconditioned spaces), heat loss or heat gains to the duct must be included in the load calculation. The duct loss will contribute additional sensible cooling load to the building. The default duct loss is set to be $10 \%$ of the total sensible cooling load, which assumes the entire duct system is in the attic. Thus, the total sensible cooling load will be 1.1 multiplying the previously calculated load. Once again, the text box is editable to allow the user to make any change on the percentage of the duct loss based on his design.

\section{Outputs of the Calculation Program}

Unlike other commercial packages, this program allows the user to view the results whenever he wants. Normally for a commercial package such as HVAC-Calc, the user can only view the results after all the required data in every field have entered. As such, it is difficult for the user to monitor the influence of each individual parameter on the cooling load and which may hinder an integrated, optimal design of the cooling system. The present program is so designed that each time when the user changes any design parameter or factor in the program, the results (cooling load of individual room as well as the total sensible and latent cooling load) are automatically updated. Thus, a user can go back and forth from the input section as well as the output section to examine the effect of each design parameter or factor on the cooling load. This is advantageous if the user is seeking an instant feedback from any specified data.

\section{(a) Transmission Cooling Load of Each Room}

The user can examine the transmission cooling load of each room by pointing the cursor to that room on the floor plan. Once selected, the room is highlighted and the result is displayed on the screen. As shown in Fig. 9, the bedroom number 2 has been selected and all the information about its transmission cooling load is displayed. By viewing the information displayed, one can examine the sensible cooling load contributed by each component (such as wall, window and roof). By summing all these sensible load components, one can obtain the total transmission cooling load of that room. In addition, when the user points the cursor to a cooling load component on the last column, the equation used to obtain that particular load is shown in the bottom of the window. Once again, this provision allows the user to keep track of which equation and properties have been used to obtain the resulting cooling load.

An additional feature of the program is that each time the orientation of the buildings is changed, the item name will change accordingly. For example, if the building is facing west, then the left wall of bedroom 2 faces south while the other wall faces east. The item names automatically reflect the direction of each component faces.

\section{(b) Total Sensible Cooling Load}

Once the transmission cooling load for each room has been calculated, other load components such as the loads contributed by occupants, appliances and infiltration are included to obtain the total sensible cooling load of the whole house. As seen from Fig. 10, seven rooms in the house (except the garage which is unconditioned) are shown in the first column. Then five major loads contribute to the total cooling load are listed in the second through sixth columns. As mentioned earlier, the occupants and appliances loads are predefined in the program. The right most column of the table shows the total sensible cooling load of each room. In addition, the loads due to duct loss (if the air distribution ducts are placed outside the conditioned space) 


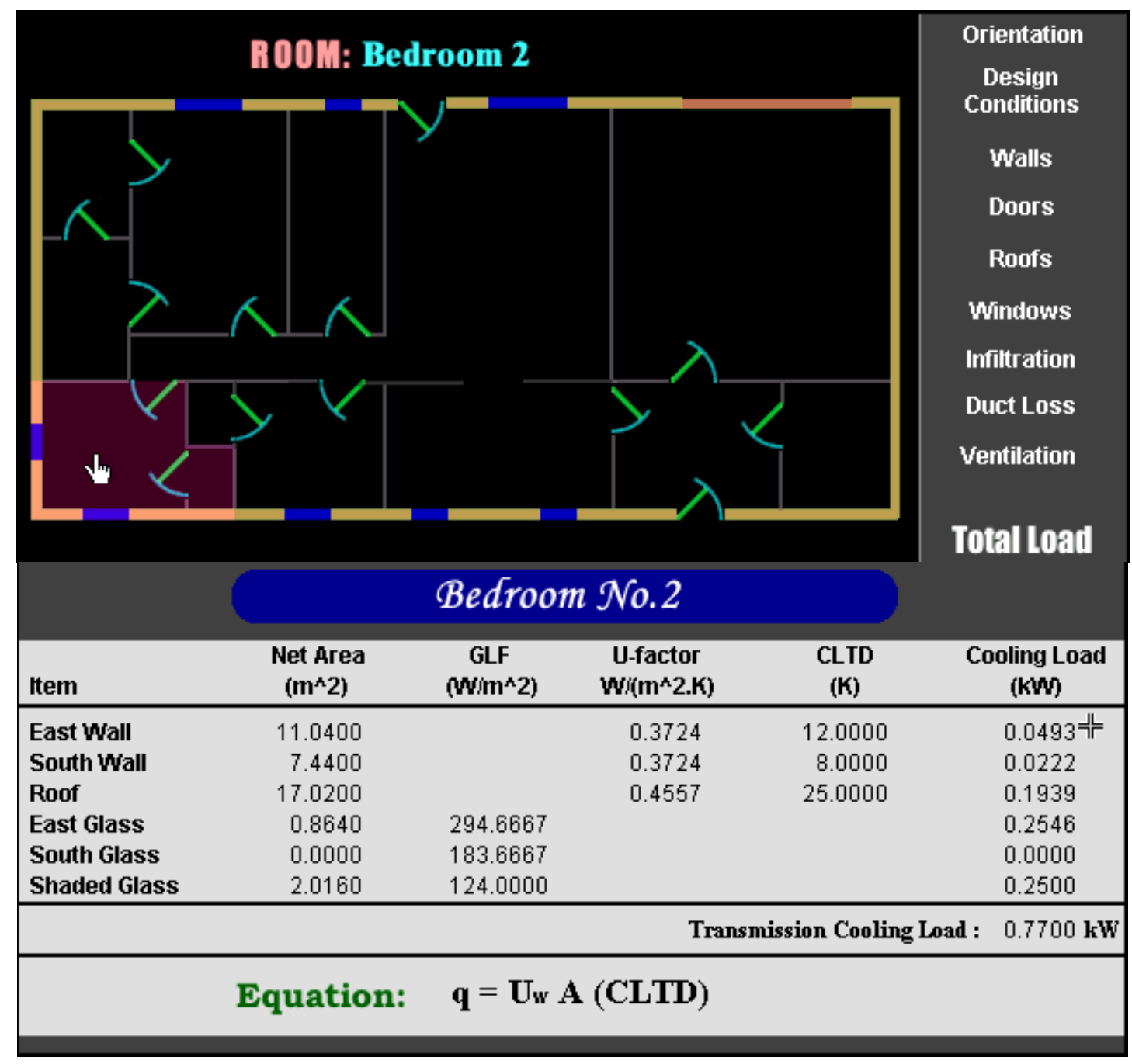

Figure 9. Transmission cooling load from bedroom No. 2.

and ventilation (if additional outdoor air is introduced to improve the indoor air quality) are also displayed. By listing all these load components in Fig. 10, the user can have a complete overview of the results. For instance, one can observe that the living room has the highest sensible cooling load of the house, which contributes more than $30 \%$ to the total load. In addition, one can see that for the sensible cooling load of the building, the contribution from window alone is comparable to those contributions from roof, walls and doors combined.

\section{(c) Total Cooling Load}

This page basically shows the total cooling load of the building after including the latent load. One can calculate the latent load using Eq. (7), by multiplying the latent load factor to the total sensible load. Once again, the help window in the bottom of the page provides useful information to the user that the latent load factor is affected by both design humidity ratio and building construction. Therefore, the user knows where to modify the design (either by changing 


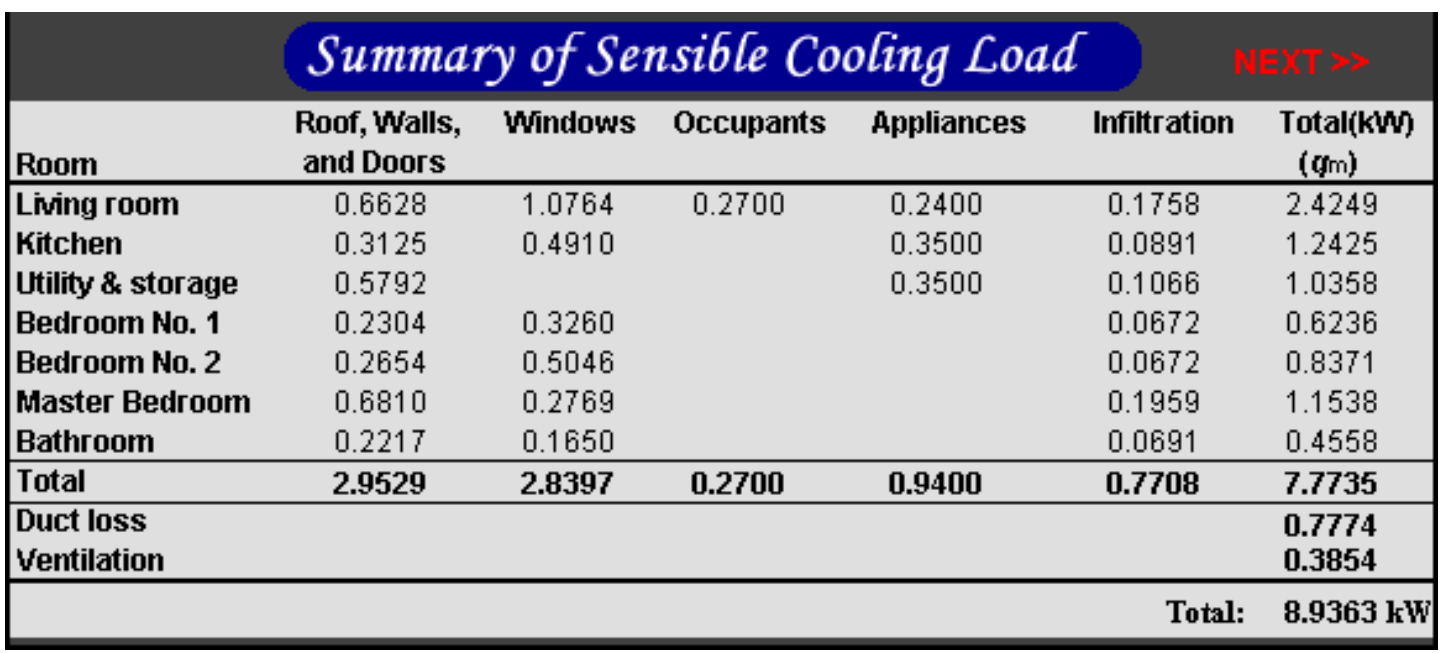

Figure 10. Summary of sensible cooling load.

the location of the house or the construction tightness) if the latent load contribution to the total cooling load is to be minimized.

In many cases, a room-by-room load calculation is not necessary unless the user wants to size the air distribution system. If only the size of the air conditioner is to be determined, it may suffice to do the load calculation for the entire house.

\section{Conclusions}

Although the features of this online program may be limited when compared with those commercial packages in the market, it does provide an effective and user-friendly way of introducing a residential cooling load calculation program to engineering and architecture students. It can be used as a stand-alone teaching aid or an add-on component for any online course of the related subjects. For the current version, the program only handles a model house with a fixed size and a specific floor plan. Nevertheless, it can still provide a good estimate of the total cooling load when it is applied to a residential building with a different size and a different floor plan. Recognize that the total cooling load is only proportional to the size (surface area and volume) of the house when all other data remain the same. Therefore, when using this program for cooling load calculation of other residential buildings, the user needs to adjust the final results by the area ratios (for roof, walls, door, and windows) and volume ratios (for $\mathrm{ACH}$ ).

If given more time and resources, the present program can be extended to include commercial buildings and completed with the heating load calculation. In addition, the dimensions and layout of the building can be made variable. The sizing of air-conditioning equipment for the building and the design of air distribution system can also be incorporated in this program. Based on the earlier responses from our students, we are confident that it can greatly enhance the learning experience of all students. 


\section{Acknowledgement}

The authors gratefully acknowledge the partial support of this work through the Grant-inAid Program provided by the American Society of Heating, Refrigerating and Air-conditioning Engineers, Inc. (ASHRAE). The support of this work from the Using Technology for the Improvement of Learning (UTIL) Program provided by the Office of the Senior Vice President and Provost at the University of Oklahoma is also gratefully acknowledged. In addition, the authors are very grateful to the reviewers for their valuable comments to further enhance the quality of the paper.

References

1. Kreider, J. F., and Rabl, A., Heating and Cooling Loads, Chapter 7, Heating and Cooling of Buildings: Design for Efficiency, McGraw-Hill, pp. 271 - 350, 1994.

2. McQuiston, F. C., Parker, J. D., and Spitler, J. D., The Cooling Load, Chapter 8, Heating, Ventilating, and Air Conditioning Analysis and Design, John Wiley and Sons, $5^{\text {th }}$ Edition, pp. $215-275,2000$.

3. McQuiston, F. C., and Spitler, J. D., Cooling and Heating Load Calculation Manual, ASHRAE, Inc., $2^{\text {nd }}$ Edition, 1992.

4. HVAC Applications, ASHRAE Handbook, SI Edition, 1999.

5. URL: http://www.hvac-software.com, HVAC Computer Systems, Ltd.

6. URL: http://www.carrier-commercial.com, Carrier Corp.

7. URL: http://www.geoexchange.org, USACERL.

8. Fundamentals, ASHRAE Handbook, SI Edition, 2001.

9. Wang, S. K., Lavan, Z., and Norton, P., Load Calculations, Air Conditioning and Refrigeration Engineering, CRC Press, pp. $59-71,2000$.

Biography

K. YEONG

Mr. Yeong currently holds a mechanical engineer position in the Affiliated Engineers, Inc. at Madison, Wisconsin. He received his B.S. and M.S. in Mechanical Engineering from the University of Oklahoma (1997 and 1999, respectively).

F. C. LAI

Dr. Lai is currently a faculty member in the School of Aerospace and Mechanical Engineering at the University of Oklahoma. He received his bachelor degree from the National Tsing Hua University in Taiwan (1978), and M.S. and Ph.D. from the University of Delaware (1985 and 1988, respectively). He joined the faculty of the University of Oklahoma in 1992. He is a member of ASEE, ASME and AIAA. 